\title{
AS CRÔNICAS EM SKETCHES BY BOZ, DE CHARLES DICKENS: UM GÊNERO HÍBRIDO QUE RETRATA O COTIDIANO ATRAVÉS DO HUMOR
}

\author{
THE SHORT STORIES IN SKETCHES BY BOZ OF CHARLES DICKENS: HYBRID \\ DISCURSIVE PRACTICES THAT PORTRAITS EVERYDAY LIFE IN A HUMOROUS WAY
}

\author{
Ana Lívia Verona \\ Universidade Federal de Uberlândia
}

RESUMO: A discussão da crônica como gênero literário surge no final do século XIX. Teóricos como Arnt (2004), Gancho (2004), Hunter (2007), Gissing (2012), Jordan (2001), Kapplan (2013), Meyer (1996), Mouta (1996), Rollemberg (2003), Schneider (2011) e Watt (1990) discorrem a respeito de elementos da narrativa nas crônicas (short stories), da construção do humor como parte do discurso e resultado direto da relação com o contexto social e cultural. O cronista, segundo Schneider (2011) "toma algum assunto, sério ou trivial, e o transforma em tema de discussão, o cronista pode assumir o papel "de historiador do cotidiano, mesmo que não esteja preocupado em fazer história", pois, para esse tipo de escritor, relatar o cotidiano e notícias com uma "abordagem sociocultural" é uma atitude comum e que resulta de suas reflexões sobre esse cotidiano, a qual é oportuna ao investigador". Hunter (2007) afirma que a ideia de arte e ação criativa em crônicas (short stories) possibilitaram que entre a brevidade do texto existisse a complexidade, diferentes formas e estruturas narratológicas aliadas à literatura, resultando num retrato de Londres, nos anos 1800, por meio de textos marcados pela descrição detalhista de situações corriqueiras, uma representação gráfica de personagens e cenas através do recurso humorístico. Esse trabalho analisa os elementos que caracterizam o gênero cronístico como híbrido, entre eles a influência de outros tipos textuais, como o texto jornalístico e teatral, como também gêneros literários. Os aspectos sociais, históricos, culturais, os fatos biográficos e o humor são importantes na construção dos temas, principalmente das personagens nas crônicas de Charles Dickens, em Sketches by Boz. Os textos selecionados foram "The four sisters" ("As quatro irmãs") e The misplaced attachment of Mr. John Dounce" ("O malfadado caso do Sr. John Dounce"). Essas crônicas apresentam temática diversa, e o humor caraterístico de Dickens, são uma observação da vida real, da rotina de ruas em Londres, da paróquia, de uma vizinhança cheia de preocupações com a vida alheia, ele formou um retrato dos costumes da burguesia vitoriana de classe média, puritana e hipócrita.

PALAVRAS-CHAVE: Charles Dickens; Crônicas; Gênero híbrido; História do cotidiano; Humor.

ABSTRACT: The discussion about short story as a literary genre anly appears at the end of the nineteenth century. Authors like Arnt (2004) Hook (2004), Hunter (2007), Gissing (2012), Jordan (2001), Kapplan (2013), Meyer (1996), Mouta (1996), Rollemberg (2003), Schneider (2011) and Watt (1990) discuss about the narrative elements in short stories (crônicas), the construction of humor as part of speech and a direct result of the relationship with the social and cultural context. According to Schneider (2011), the writer 


\section{Revista do SELL}

v. 5 , no. 2

ISSN: $1983-3873$

of short stories "takes some matter, serious or trivial, and transforms it into subject of discussion, even if he is not concerned about making history. For this kind of writer, report daily and news with a "sociocultural approach" is a common attitude and the result of his reflections about everyday life. Hunter (2007) states that the idea of art and creative action in short stories permit the brevity and the complexity in the text. The different shapes and narratological structures, combined with literature, result in a portrait of London in the 1800 s, once the texts marked by detailed description of everyday situations, graphical representation of characters and scenes with humor. This paper analyzes the characteristics of the short story as hybrid genre, including the influence of other text types, such as journalistic and theater text, as well as literary genres. The social, historical and cultural aspects, biographical facts and humor are important in the construction of themes and characters in the book of Charles Dickens, Sketches by Boz. The short stories selected were "The four sisters" and "The misplaced attachment of Mr. John Dounce". These texts have different themes and the peculiar humor of Dickens in his observation of real life, the routine of streets in London, the parish, and a neighborhood full of concerns about others' lives that is possible to form a picture of the puritanical and hypocritical Victorian middle class.

KEYWORDS: Charles Dickens; Short story; Hybrid discursive practices; History of everyday life; Humor.

\section{Considerações iniciais}

Dickens foi um autor de grande importância no século XIX, iniciou sua carreira literária escrevendo crônicas para os jornais The Morning Chronicle, The Evening Chronicle, algumas revistas e periódicos. De acordo com George Gissing (2012, p. 07), Charles Dickens assinava os textos como "Boz" ou "Boses", que eram as formas como ele pronunciava o nome "Moses" (Moisés) quando criança. Outros autores da Era Vitoriana, além de Dickens, de acordo como Adrian Hunter (2007), como William Thackeray e Elizabeth Gaskell, dedicaram-se ao gênero crônica. Esses textos serviam como entretenimento e refletiam as características da sociedade nesse período, induzindo ao diálogo e reflexão de assuntos relevantes como hipocrisia religiosa e moral por meio de assuntos cotidianos.

As crônicas de Dickens, segundo Marcelo Rollemberg (2003, p. 8-9) continham relatos do cotidiano, das paróquias, uma observação da vida real, da rotina das ruas em Londres, de uma vizinhança cheia de preocupações com a vida alheia, retratos das condições sociais da época, dos costumes da burguesia vitoriana de classe média, os quais são criticados devido aos valores puritanos e hipócritas apresentados ao leitor por 


\section{Revista do SELL}

v. 5 , no. 2

ISSN: $1983-3873$

Dickens de forma crítica e irônica. Continham também reportagem e ficção; personagens tipicamente londrinas do século XIX, assim como "apresentavam uma visão irônica, capacidade de observação inédita, antecediam o realismo e também o surrealismo, em uma época em que o romantismo ainda era o gênero mais recorrente". Esses textos foram reunidos em Sketches by Boz, primeiro livro do escritor publicado em 1836, quando ele estava com 24 anos; o qual foi marcado pela habilidade de Charles Dickens em usar o humor para descrever, com perfeição e detalhes, situações, cenas e personagens corriqueiros da cidade de Londres, o que fez com que os leitores da época se identificassem com a realidade descrita por ele.

Apresenta-se, como exemplo de retrato humorístico em Scketches by Boz, a construção do tema e das personagens nas crônicas "As quatro irmãs" (The four sisters) e "O malfadado caso do Sr. John Dounce" (The misplaced attachment of Mr. John Dounce) ${ }^{1}$, de Dickens; assim como, ressalta-se os elementos discursivos, sociais, históricos e culturais relevantes para a narrativa.

\section{A Literatura e o gênero crônica}

A discussão sobre a definição e função da Literatura, assim como a constituição da Teoria Literária é antiga; pode-se afirmar que remete ao século IV na Grécia antiga, com a filosofia de Platão, Aristóteles e perdura até a atualidade. O teórico Terry Eagleton (2003, p.11) discute as possibilidades e impossibilidades de se definir a Literatura: "A definição de literatura fica dependendo da maneira pela qual alguém resolve ler, e não da natureza daquilo que é lido". Ele acrescenta que as obras literárias são interpretadas de acordo com o interesse de quem as lê ou estuda, o que talvez seja o fator responsável por algumas delas apresentarem "valor através dos séculos".

As obras literárias seriam reescritas pelas sociedades que as leem, segundo Eagleton (2003, p. 16, 17), clássicos como Homero e Shakespeare seriam construídos não como eram no período histórico a que pertenciam, mas de acordo com interesses,

\footnotetext{
${ }^{1}$ A crônica, "As quatro irmãs", foi publicada pela primeira vez em 18 de junho de 1835 , e "O malfadado caso do Sr. John Dounce", em 25 de outubro de 1835, ambas do primeiro volume de Scketches by Boz e traduzidas, no Brasil, por Marcelo Rollemberg, em Retratos Londrinos (2003).
} 


\section{Revista do SELL}

v. 5 , no. 2

ISSN: $1983-3873$

preocupações e valores dos leitores de determinada sociedade e período histórico.

Nenhuma obra, e nenhuma avaliação atual dela, pode ser simplesmente estendida a novos grupos de pessoas sem que, nesse processo, sofra modificações, talvez quase imperceptíveis. E essa é uma das razões pelas quais o ato de se classificar algo como literatura é extremamente instável. (EAGLETON, 2003, p. 17)

O conceito de literatura, como se conhece na modernidade, surgiu em fins do século XVIII, porém foi no século XIX, período correspondente ao Romantismo, que esse conceito ganhou contornos mais específicos, definições de gêneros, e o romance, inicialmente publicado nos jornais, como folhetins, começou a ganhar destaque.

Eagleton (2003, p. 27, 33) afirma que a ascensão da língua inglesa e fatores históricos levaram a Inglaterra a assumir uma posição econômica dominante no sistema capitalista também recém-criado e a Literatura, assim, assumiu a tarefa ideológica de "transformar a sociedade em nome das energias e valores representados pela arte" e que "podia proporcionar um antídoto poderoso ao excesso religioso e ao extremismo ideológico".

De forma sucinta, o cenário histórico e econômico do século XIX foi marcado por revoluções, assim como transformações impulsionadas pela I Revolução Industrial iniciada na Inglaterra. O desenvolvimento de máquinas; proliferação de fábricas; revoluções burguesas; avanços na medicina; novas invenções como a fotografia; 0 desenvolvimento da imprensa, o surgimento de inúmeros periódicos, jornais e revistas, impulsionados pelo aumento do índice de alfabetização da população. Embora, a classe proletária inglesa tivesse pouco acesso à educação; a modernidade e o progresso da sociedade acentuou a desigualdade social, as más condições de trabalho da classe proletária e concentração populacional nas cidades.

No âmbito literário, o Romantismo, no século XIX, serviu aos escritores como meio de crítica ao capitalismo, ao avanço da sociedade sem o devido planejamento, às diferenças sociais, à corrupção, entre outros. O folhetim foi o responsável pelo surgimento das crônicas e contos nos jornais tanto na Europa, como no Brasil, assim como viabilizou debates culturais e de cunho histórico, o que resultou na descrição histórica, política e social de uma época. Segundo Héris Arnt (2004, p. 47, 48), a presença da literatura e de 


\section{Revista do SELL}

v. 5 , no. 2

ISSN: $1983-3873$

escritores em jornais "foi um fenômeno universal" que marcou o século XIX, e eles estavam sempre de alguma forma "engajados num movimento de denúncia e crítica das condições sociais".

Eagleton (2003, p. 281) propõe que a literatura deveria ser estudada como uma escrita no campo do que Michel Foucault denomina de práticas discursivas, o que significaria retomar princípios da retórica.

A retórica, que foi a forma de análise crítica conhecida desde a sociedade antiga até o séc. XVIII, examinava a maneira pela qual os discursos são constituídos a fim de obter certos efeitos. Ela não se preocupava se o objeto era oral ou escrito, poesia ou filosofia, ficção ou historiografia: seu horizonte era apenas o campo da prática discursiva na sociedade como um todo, e seu interesse particular estava em ver tais práticas como formas de poder e de desempenho. (EAGLETON, 2003, p. 282)

De acordo com a afirmação de Eagleton (2003, p. 16) ler as crônicas de Charles Dickens, escritor pertencente ao século XIX, é também reescrevê-las de acordo com a sociedade, o período histórico, os interesses, preocupações e valores de quem as leem. $A$ Crônica do século XIX, de acordo com Adrian Hunter (2007, p. 1-11) passa a ter um espaço na literatura e no mercado, antes limitado somente ao romance, o qual ainda influenciava profundamente esse gênero. A crônica era vista por Dickens como o resumo de um romance, apresentando a mesma estrutura de narrativa; a ideia de arte e ação criativa possibilita que o texto seja breve e também complexo, com diferentes formas e estruturas narratológicas, o que resultou no conceito de crônicas em inglês, literary sketches ou short stories.

O crítico Antônio Candido (1992, p. 13-22) afirma que "A crônica não é um 'gênero maior'. Nem se pensaria em atribuir o Prêmio Nobel a um cronista, por melhor que fosse". A crônica para Candido (1992, p. 13-22) é efêmera e ele acrescenta: "o fato de ficar tão perto do dia-a-dia age como quebra do monumental e da ênfase".

C. V. Gancho (2004, cap. 1, p. 05) define a crônica como "um texto híbrido e pode apresentar ou não os elementos de uma narrativa completa; uma crônica pode contar, comentar, descrever, analisar", e descreve algumas características da crônica: "texto curto, leve, que geralmente aborda temas do cotidiano".

Jorge de Sá (2005, p. 11) propõe que a crônica, como parte de uma narrativa 


\section{Revista do SELL}

v. 5 , no. 2

ISSN: $1983-3873$

curta, é "soma de jornalismo e literatura", e afirma que, ao levar em conta a rotina, o cotidiano e os pequenos detalhes, com "lirismo reflexivo, o cronista capta esse instante brevíssimo que também faz parte da condição humana" e transforma situações simples em um "diálogo sobre a complexidade das nossas dores e alegrias. Somente nesse sentido crítico é que nos interessa o lado circunstancial da vida. E da literatura também".

Arnt (2004, p. 48, 49) expõe que o gênero narrativo da crônica ficcionaliza a realidade e contribui para que esse texto seja um "espelho da sociedade de determinada época". Assim como, C. I. Schneider (2011, p. 4) descreve que o cronista "toma algum assunto, sério ou trivial, e o transforma em tema de discussão", pois, para esse tipo de escritor, relatar o cotidiano e notícias com uma "abordagem sociocultural" é uma atitude comum e que resulta de suas reflexões sobre esse cotidiano aliada ao tempo presente, demonstrando que "a relação da crônica com a história do cotidiano parece ser oportuna ao investigador".

Portanto, quando se fala em crônicas, pode-se afirmar que são textos híbridos, por possuírem caraterísticas de outros gêneros textuais e literários, efêmeros e podem ser vinculados em meios também efêmeros, como os jornais, assim como representam um período histórico, cultural e social específico de uma sociedade.

\section{Charles Dickens: a importância de fatos biográficos na obra do escritor}

Muitos livros e artigos foram publicados sobre a vida de Charles Dickens, um escritor notável e com obras consideradas clássicos da literatura (Cockshut, 2009, p. 11). Alguns autores que se dedicaram a escrever sobre Dickens foram Jordan (2001), Cockshut (2009), Gissing (2012), Kaplan (2013), entre outros, os quais não discordam da genialidade do escritor, que inspirou escritores, como Dostoievski, por exemplo. As biografias ou estudos sobre Charles Dickens apresentaram a comparação entre ele e Shakespeare - ambos meninos pobres da Inglaterra e que se tornaram grandes escritores. Dickens foi, também, um grande admirador de Shakespeare.

De acordo com Kaplan (2013, p. 32) desde criança Charles Dickens era reconhecido como um questionador, e queria ser reconhecido pela sua obra. Dickens chegou a queimar as correspondências trocadas durante anos com amigos, familiares, 


\section{Revista do SELL}

v. 5 , no. 2

ISSN: $1983-3873$

mulheres, pois presumia que certamente essas cartas seriam publicadas e seu desejo era de que apenas sua obra falasse por ele.

Jordan (2001), Cockshut (2009), Gissing (2012) e Kaplan (2013) ressaltam que Dickens, enquanto criança foi obrigado pelos pais a trabalhar em um fábrica de sapatos enquanto deveria frequentar a escola; assim como as relações e tratamento dispensado por Dickens às mulheres; o desejo do escritor de manter a vida pessoal secreta ao destacar a vida pública como escritor.

Dickens começou a escrever como jornalista e cronista freelance, depois escreve, também, para jornais importantes de Londres. Com relação ao trabalho como jornalista, Dickens foi reconhecido a partir de março de 1832, quando começou a trabalhar como repórter para os jornais The True Sun e The Mirror of Parliament, enquanto se dedicava a outras funções, como roteiros de teatro, crônicas, e reportagens em geral. (KAPLAN, 2013, cap. 5, p. 02)

De acordo com Jordan (2001, p. 18), em 1834 Dickens se tornou repórter do jornal The Morning Chronicles e The Evening Chronicles; durante dois anos, de 1834 a 1836, Dickens se dividia entre as reportagens e as crônicas. Foi durante esses dois anos que ele reuniu as crônicas que escreveu, as quais, com a oferta do editor John Macrone, foram publicadas nos dois volumes de Sketches by Boz. O sucesso da publicação de Sketches by Boz foi descrito por Kaplan (2013, cap. 3, p. 03) como inesperado e Gissing (2012, cap. II, p. 06) declarou que o livro Sketches by Boz só poderia ser o resultado do trabalho de um escritor muito talentoso.

Slater (1983, p. 232- 233) afirma que Dickens refletiu a realidade social da classe média e da classe média-baixa de Londres; as personagens femininas eram descritas por ele com humor característico, especialmente quando tratava das atividades femininas e dos atributos mercenários das mulheres. Embora o século XIX tenha produzido grandes transformações e as mulheres tenham começado a conseguir a independência financeira e do sexo masculino, Dickens retratou mulheres de classe social baixa ou relacionadas à burguesia decadente, descrita pelo escritor como hipócrita e grotesca.

Jordan (2001, p. 22) diz que estilo dos textos em Sketches by Boz é resultado das experiências anteriores de Dickens como repórter e dos fatos da vida pessoal do escritor. Sketches by Boz foi descrito, também, como um retrato de Londres, uma representação 


\section{Revista do SELL}

v. 5 , no. 2

ISSN: $1983-3873$

gráfica de personagens e cenas em que Dickens usou, perfeitamente, os elementos do teatro aliados à literatura.

\section{Aspectos históricos, sociais, culturais e o humor em Sketches by Boz}

De acordo com Margarida A. S. V. Mouta (1996, p. 33-35, 114, 115) o humor é resultado direto da relação com o contexto situacional, social e cultural, o que envolve, também, a linguagem e o uso (subversivo) dessa, resultando em procurar indícios da especificidade do humor verbal no discurso; essa concepção concorda com os estudos de Michel Focault sobre as práticas discursivas. Ou ainda, de acordo com Henri Bergson (1983, p. 60) que apresenta a ideia de definir o humor, o cômico através da degradação da natureza humana, modelo seguido pela paródia na retórica clássica.

Dickens, segundo A. O. J. Cockshut (2009, p. 17, 18), aplicou o humor à condição humana, ou seja, retratou com humor a situação das personagens, as quais eram dificilmente passíveis de classificação em categorias morais, e nesse sentido o humor apresentado por Dickens foi criativo e original; oriundo da idiossincrasia da linguagem. Dickens apresentava pouca moralidade ao analisar as loucuras típicas e as inconsistências da natureza humana; em alguns momentos conduzindo ao absurdo e ao fantástico, mas de forma extremamente real para o leitor.

George Gissing (2012, p. 14) também descreveu o humor como a característica marcante de Sketches by Boz e o que faz dele um texto original. Quanto às personagens, elas apresentavam vida, e poderiam ser encontradas com facilidade na atualidade, ainda que afetadas pelo tempo, devido ao retrato perfeito que Dickens deixou delas através do poder do riso.

Duas crônicas do livro Sketches by Boz, de Charles Dickens foram selecionadas para exemplificar o humor no texto de Dickens, com destaque na descrição feita das personagens: "As quatro irmãs", de 18 de junho de 1835, e "O malfadado caso do Sr. John Dounce", de 25 de outubro de 1835. 


\section{Revista do SELL}

v. 5 , no. 2

ISSN: 1983-3873

\section{Análise da crônica "As quatro irmãs"}

A crônica de Dickens, "As quatro irmãs", relata a mudança das Senhoritas Willis para a rua da paróquia, 13 anos antes, posteriormente, narra os acontecimentos e a especulação dos vizinhos com relação ao casamento de uma das irmãs e o ocorrido 45 dias depois, o nascimento da filha do casal. O texto tem estilo afirmativo, característica encontrada também no texto jornalístico e uma linguagem carregada de humor, ora irônico, ora sarcástico.

Pode-se afirmar que o tema desenvolvido na crônica é universal devido ao recurso discursivo do humor e pela crítica que tece às classes sociais, a questão da mulher, a idade para o casamento, e os interesses relacionados ao matrimônio, os quais parecem pertinentes na atualidade. Apesar das mudanças de padrões familiares e a independência feminina, as mulheres ainda são cobradas socialmente a constituir família, se casar, mesmo que essas não sejam as opções escolhidas por elas. Essa cobrança social só aumenta com o tempo.

A relação de Charles Dickens com as mulheres, de acordo com alguns estudiosos, influenciou a visão e a construção das personagens do escritor. Fred Kaplan (2013, p. 28) declarou que a relação de Dickens com as mulheres, tanto na vida pessoal quanto na ficção, nunca foi simpática aos conceitos modernos; ele associava todo o sofrimento de trabalhar em uma fábrica de sapatos, enquanto ainda era criança, e o fato de parar de estudar, à indiferença de sua mãe com relação à situação dele; a mãe era descrita por Dickens como uma mulher fria, e para ele essa indiferença também foi a responsável pela falência do pai. A relação de Dickens com a mãe influenciou 0 estereótipo de muitas mulheres na obra ficcional do escritor.

Os estereótipos femininos apresentados por Dickens estavam de acordo com a visão masculina, e, no caso das Senhoritas Willis, da crônica "As quatro irmãs", a descrição de Slater (1983, p. 232) aplica-se perfeitamente: mulheres que já não eram jovens, com características nada atraentes, e que desejavam muito o casamento, mas estavam escondidas atrás de uma hipocrisia da sociedade e se desculpavam dizendo terem medo de não estarem preparadas para o matrimônio. ${ }^{2}$

Minha tradução do original: "Middle-aged spinters yielding to romance (...) unattractive Young womem - 'frights', to use the 


\section{Revista do SELL}

v. 5 , no. 2

ISSN: $1983-3873$

O texto é narrado em primeira pessoa, o narrador não é a personagem principal, mas narra acontecimentos dos quais participou, sem grande destaque, assim como apresenta julgamentos sobre o comportamento das personagens.

Nosso trabalho como cronistas paroquiais, contudo, está acima de qualquer coisa, e somos obrigados a declarar que, desde aquela época, as autoridades em casos matrimoniais consideravam que a mais jovem das senhoritas Willis estava em uma situação bem complicada, enquanto a mais velha delas já estava definitivamente descartada, como se tivesse sido esquecida pela humanidade. ${ }^{3}$ (DICKENS, 2003, p. 43)

O tempo retratado na crônica é psicológico, segue de acordo com a vontade do narrador, o qual usa o flashback para descrever o período em que as senhoritas Willis se mudaram para a rua, 13 anos antes, e posteriormente usado para narrar os acontecimentos que culminaram no casamento e o ocorrido 45 dias depois, o nascimento da filha do casal. O trecho original e a tradução demostram esta volta no tempo da narrativa: "Falemos, então, das quatro senhoritas Willis, que se estabeleceram em nossa paróquia há 13 anos". ${ }^{4}$

A sequência de expressões usadas por Dickens para descrever as personagens principais, as Senhoritas Willis (Misses Willisses), estão carregadas da visão social, histórica e cultural da época. A sequência de expressões usadas por Dickens forma um retrato cômico e sarcástico das personagens principais, ou da personagem, uma vez que são quatro irmãs, mas, nas palavras de Dickens, "They seemed to have no separate existence/ Elas pareciam não ter vida independente". As expressões em negrito dos trechos selecionados abaixo, destacam o emprego dos adjetivos, usados para compor 0 retrato humorístico das personagens, e das aspas ("') ("), que não foram usadas para destacar gíria ou vocábulo estrangeiro, antes se apresentaram como recurso do discurso para enfatizar o humor e o sarcasmo no texto.

\footnotetext{
Victorians own word - who presume to aspire to matrimony". (SLATER, 1983, p. 232)

Tradução do original: Our duty as faithful parochial chroniclers, however, is Paramount to every other consideration, and we are bound to state, that thirteen years since, the authorities in matrimonial cases, considered the youngest Miss Willis in a very precarious state, while the eldest sister was positively given over, as being far beyond all human hope. (DICKENS, 2000, p. 14-19, meu grifo)
}

Tradução do original: The four Miss Willises, then, settled in our parish thirteen years ago. (DICKENS, 2000, p. 14-19) 


\section{Revista do SELL}

v. 5 , no. 2

ISSN: $1983-3873$

(...) mesmo há 13 anos as senhoritas Willis já estavam longe de ser jovens.

(...)somos obrigados a declarar que, desde aquela época, as autoridades em casos matrimoniais consideravam que a mais jovem das senhoritas Willis estava em uma situação bem complicada.

(...) a mais velha delas já estava definitivamente descartada, como se tivesse sido esquecida pela humanidade.

(..) quatro damas imensamente ricas.

(...) A mais velha das senhoritas Willis tornou-se extremamente malhumorada - o que fez com que todas as outras logo ficassem malhumoradas também. A mais velha das senhoritas Willis tornou-se resmungona e muito religiosa - as outras irmãs ficaram decididamente resmungonas e carolas. Qualquer coisa que a mais velha fazia, as outras faziam também. E qualquer coisa que alguma outra pessoa fizesse, elas desaprovavam completamente. $\mathrm{E}$ assim iam vegetando, vivendo numa harmonia polar entre si. Vez por outra estendiam sua vidinha gelada aos vizinhos, quando acontecia de saírem ou de receberem alguma visita "sossegada" em casa. (DICKENS, 2003, p. 43-49, meu grifo) ${ }^{5}$

A alusão às três Graças, mais uma, e às três Parcas, mais uma irmã, tiveram como função descrever de forma sarcástica a condição da mulher na burguesia londrina. Segundo o Dicionário de mitologia grega (2005, p. 75), as três Graças são figuras mitológicas que representam a beleza feminina e "espalham a alegria na natureza e no coração dos homens e até no dos deuses". O objetivo dessa citação mitológica é ironizar a condição das quatro irmãs, pelo paradoxo, uma vez que essa imagem das três graças, mai uma é contrária à toda descrição feita dessas personagens.

Gissing (2012, cap. 2, p. 05) afirmou que no período em que Charles Dickens frequentou a escola e durante as leituras pessoais, o escritor estudou os clássicos, os quais aparecem em seus livros, aludindo a ironia. ${ }^{6}$

O uso da expressão "o tempo passa, inexorável, sem poupar ninguém", a qual no texto original em inglês é um provérbio: "time and tide wait for no man", é definido pelo

\footnotetext{
$5 \quad$ Tradução do original: (...) even thirteen years ago the Miss Willises were far from juvenile; (...) that thirteen years since, the authorities in matrimonial cases, considered the youngest Miss Willis in a very precarious state; (...) the eldest sister was positively given over, as being far beyond all human hope; (...) four maiden ladies of immense property; (...) The eldest Miss Willis grew illtempered and religious - the four Miss Willises were ill-tempered and religious directly. Whatever the eldest did, the others did, and whatever anybody else did, they all disapproved of; and thus they vegetated -living in Polar harmony among themselves, and, as they sometimes went out, or saw company 'in a quiet-way' at home, occasionally icing the neighbours. (DICKENS, 2000, p. 14-19, meu grifo)

${ }^{6}$ Do original: (...) he has received 'classical education' (...) There is no mistaking the personal note in those passages of his books which treat of, or alude to, Greek and Latin studies in a satirical spirit. Gissing (2012, cap. 2, p. 05)
} 


\section{Revista do SELL}

v. 5 , no. 2

ISSN: $1983-3873$

dicionário Oxford como: "provérbio: Se não aproveitar uma situação favorável, provavelmente não terá outra chance"7 0 Phrase dictionary: The Phrase Finder definiu 0 provérbio como: "Ninguém é tão poderoso que consiga parar a marcha do tempo"8. Esse provérbio não é recorrente em português, como o é, ainda na atualidade, em inglês. A citação desse provérbio parece ter objetivado o sarcasmo diante da situação das senhoritas Willis para o casamento, mas também constituiu uma marca histórica e cultural na crônica. De acordo com o Phrase dictionary: The Phrase Finder, a origem desse provébio é de 1225, tendo sido registrada por St. Marher, com referência à história do rei dinamarquês Canuto, enterrado na Catedral de Whinchester England: "And te tide and te time pat tu iboren were, schal beon iblescet"; traduzido para o inglês como "the tide abides for, tarrieth for no man, stays no man, tide nor time tarrieth no man"; e popular na forma em que ocorre na crônica. ${ }^{9}$

No tocante ao enredo, o conflito da crônica se fez presente em todo texto, mantendo o suspense e a curiosidade através do dilema: quem, das quatro irmãs, seria a esposa do Mr. Robinson.

O noivo, Mr. Robinson/Sr. Robinson, personagem secundária, teve enfatizadas as condições financeiras através da escolha dos adjetivos, o que foi usado como recurso discursivo para enfatizar o humor sarcástico, assim como o uso apenas de parênteses. Esses recursos discursivos tecem crítica à hipocrisia, aos interesses ligados ao casamento e ao materialismo, características fortes da burguesia londrina, como mostra o trecho: "Sr. Robinson (um cavalheiro que trabalhava numa repartição pública e que tinha, além do mais, um bom salário e alguns bens ${ }^{10 "}$

O diálogo, recurso discursivo predominante no texto teatral complementa a construção do humor no texto ao permitir que as personagens secundárias, vizinhos e

\footnotetext{
${ }^{7}$ Minha tradução do original: proverb: If you don't make use of a favourable opportunity, you may never get the same chance again." (Phrase dictionary: The Phrase Finder)

${ }^{8}$ Minha tradução do original: "No one is so powerful that they can stop the march of time" (Phrase dictionary: The Phrase Finder)

${ }^{9}$ Do original: "The notion of 'tide' being beyond man's control brings up images of the King Canute story. He demonstrated to his courtiers the limits of a king's power by failing to make the sea obey his command. That literal interpretation of 'tide' in 'time and tide' is what is now usually understood, but wasn't what was meant in the original version of the expression. 'Tide' didn't refer to the contemporary meaning of the word, that is, the rising and falling of the sea, but to a period of time. When this phrase was coined tide meant a season, or a time, or a while. The word is still with us in that sense in 'good tidings', which refers to a good event or occasion and whitsuntide, noontide etc." (The Phrase Finder)

10 Tradução do original: "Mr. Robinson (a gentleman in a public office, with a good salary and a little property of his own, besides)". (DICKENS, 2000, p. 14-19)
} 


\section{Revista do SELL}

v. 5 , no. 2

ISSN: $1983-3873$

vizinhas, emitam opiniões sobre a união das quatro irmãs que pareciam apenas uma pessoa, o assunto do casamento, o dia do casamento e as especulações sobre quem seria, então, a esposa.

As personagens, em geral são planas e caricatas, não apresentam complexidade, e são sempre marcadas por adjetivos, os quais marcam o humor pela degradação das personagens: the old lady/a velha senhora; the old gentleman of silk-worm notoriety/o cavalheiro idoso de natureza ardilosa; the lady at $n^{\circ}$ 19/ a senhora do $n^{\circ} 19$; the spinster of an uncertain age/ a solteirona do no 16; the servants/as criadas; a fat old woman/ a senhora velha e gorda.

Portanto, o retrato humorístico da condição das quatro irmãs é feito através de recursos discursivos como os adjetivos, aspas, frases interrogativas e os diálogos inseridos pelo narrador. O último parágrafo da crônica o desfecho é apresentado: a solução do problema, de forma irônica e sarcástica, é descrita pelo narrador como um feito, o fato da senhorita Willis, a mais jovem delas conseguir engravidar antes do casamento, de um cavalheiro de posses, e se tornar, então, a Sra. Robinson.

\section{Análise da crônica "O malfadado caso do Sr. John Dounce"}

A crônica de Dickens, "O malfadado caso do Sr. John Dounce" relata a história do Sr. John Dounce, descrito como "velho namoradeiro" e "velho gabola", o qual levava a vida tranquila de um burguês viúvo do século XIX, em companhia de outros três amigos inseparáveis, e também descritos como namoradeiros e gabolas, o Sr. Harris, Sr. Jennings e o Sr. Jones. O texto, assim como em "As quatro irmãs" tem estilo afirmativo, como o do texto jornalístico e humor.

"O malfadado caso do Sr. John Dounce" tem como tema os velhos que se apaixonam por mulheres mais novas, as quais se mostram interesseiras e o que seria um comportamento humano que perdura até a atualidade. Pode-se dizer, então, que "As quatro irmãs" abordam as mulheres que passaram da idade de se casar e os interesses financeiros relacionados ao casamento e faz contraponto com o texto sobre o Sr. John Dounce através humor usado para criticar as classes sociais, o homem, a mulher e a hipocrisia de relacionamentos amorosos. 


\section{Revista do SELL}

v. 5 , no. 2

ISSN: $1983-3873$

Dickens, no texto "O malfadado caso do Sr. John Dounce", usa o narrador e diversos adjetivos para iniciar o retrato humorístico das personagens, assim o enredo da crônica apresenta primeiro: a classificação de uma categoria de homens da sociedade londrina, "os velhos namoradeiros"; esses são, então, classificados como velhos gabolas festeiros ou discretos (velhos gabolas são aqueles que gostam de contar vantagem, fanfarrões). Em seguida, é apresentada a descrição dos quatro senhores, Sr. Dounce, Sr. Harris, Sr. Jennings e o Sr. Jones, como também a rotina deles enquanto frequentadores do "Quadrant e Regent Street durante o dia e os teatros (especialmente os dirigidos por mulheres) à noite. " 11 A rotina do Sr. John Dounce é descrita como um relógio, sempre as mesmas atividades e lugares em companhia dos três amigos ou das três filhas. Por fim, descreve-se o dia que conheceu a moça jovem, por volta de 25 anos de idade, vestida de azul e que trabalhava na loja de ostras. Aos poucos o Sr. John Dounce se relacionava apenas com a moça da loja de ostras, a qual após lucrar tudo que podia com essa relação dispensou o Sr. Dounce. Ele serviu de chacota e "exemplo vivo para todos os velhos namoradeiros". ${ }^{12}$

O texto é narrado em primeira pessoa, como em "As quatro irmãs", o narradorpersonagem não apresenta grande destaque, porém tece julgamentos sobre as personagens usados como recursos para compor o retrato sarcástico das personagens.

O tempo é cronológico, seguindo uma sequência de fatos: da rotina dos quatro amigos, até o Sr. Dounce conhecer a jovem da loja de ostras e ser dispensado. O texto é classificado como crônica, mas apresenta características da estrutura de uma fábula ou conto de fadas, pois o desfecho é apresentado com uma moral ou lição para a história, indicando o hibridismo do gênero cronístico. Através das conjunções e repetições de moral da história, o narrador demonstra o humor sarcástico com relação ao enredo e tema do texto, "Agora vem a moral da história - pois que a história tem uma moral, no fim das contas". 13

\footnotetext{
${ }^{11}$ Do original: "The gay old boys, are paunchy old men in the disguise of young ones, who frequent the Quadrant and Regent-street in the day-time: the theatres (especially theatres under lady management) at night;" (DICKENS, 2000, p. 14-19).

12 Do original: "a living warning to all uxorious old boys" (DICKENS, 2000, p. 14-19).

${ }^{13}$ Do original: "Now comes the moral of the story—for it has a moral after all" (DICKENS, 2000, p. 14-19).
} 


\section{Revista do SELL}

v. 5 , no. 2

ISSN: $1983-3873$

O diálogo marca a cena descrita em detalhes entre o Sr. John Dounce e a jovem de vestido azul por intermédio do narrador. Esses diálogos e descrições detalhadas com objetivo de construir cenários mentais são recorrentes no texto teatral e é um recurso usado para enfatizar o humor sarcástico e a ironia. A repetição da expressão "uma dúzia de ostras de oito pence" e "mais meia dúzia de ostras de oito pence"14 (atualmente seriam menos de seis reais) objetiva satirizar a atitude do Sr. Dounce perante a jovem pela ênfase na quantia gasta, assim como a decadência do burguês.

A personagem principal é o Sr. John Dounce, descrito pelo narrador com um humor caricato e sarcástico por meio dos recursos discursivos como os adjetivos, aspas e parênteses.

\footnotetext{
${ }^{14}$ Do original: "(...) a dozen of those at eight pence in less than no time"; "(...) Mr. John Dounce eat half-a-dozen more of those at eight pence” (DICKENS, 2000, p. 14-19).
} 


\section{Revista do SELL}

v. 5 , no. 2

ISSN: $1983-3873$

melancólico de miséria consumada e um exemplo vivo para todos os velhos namoradeiros. (DICKENS, 2003, p. 43-49, meu grifo) ${ }^{15}$

As personagens secundárias são usadas para enfatizar, pelo humor, a mediocridade da personagem principal. Os três amigos do Sr. Dounce são "o Sr. Harris, dono da papelaria jurídica, e o Sr. Jennings, fabricante de becas (dois velhos namoradeiros como ele), e Jones, assistente da promotoria (que adorava beber rum), uma companhia fundamental e um grande contador de anedotas! ".16 Os adjetivos enfatizam a classes social das personagens e agem como uma crítica ao comportamento burguês, assim como, os parênteses introduzem comentários com fins sarcásticos e irônicos a esse comportamento.

Outra personagem secundária de suma importância é a jovem por quem o Sr. Dounce se apaixona, a qual é descrita como "uma jovem por volta de seus 25 anos de idade, toda vestida de azul e totalmente sozinha - esplêndida criatura, rosto charmoso e talhe adorável! ". Em outro momento, afirma-se: "Se a jovem parecera linda à noite, mostrou-se totalmente irresistível de dia". ${ }^{17} \mathrm{E}$ por fim, no desfecho do texto o narrador aponta o estereótipo feminino construído por Dickens, o qual se baseou na relação com a mãe; para ele, ela era a responsável pelo sofrimento dele e a falência do pai (Fred Kaplan, 2013, p. 28), assim como é descrita a moça jovem de vestido azul, a responsável pelo sofrimento e a decadência do Sr. John Dounce.

${ }^{15}$ Do original: "Mr. John Dounce was an old boy of the latter class (we don't mean immortal, but steady), a retired glove and braces maker, a widower, resident with three daughters - all grown up, and all unmarried-in Cursitorstreet, Chancery-lane. He was a short, round, large-faced, tubbish sort of man, with a broad-brimmed hat, and a square coat; and had that grave, but confident, kind of roll, peculiar to old boys in general. Regular as clockwork (...);The sad-dog sort of feeling came strongly upon John Dounce (...); (...) a change came over the spirit of John Dounce's dream. He bought shirt-pins; wore a ring on his third finger; read poetry; bribed a cheap miniature-painter to perpetrate a faint resemblance to a youthful face, with a curtain over his head, six large books in the background, and an open country in the distance (this he called his portrait); 'went on' altogether in such an uproarious manner, that the three Miss Dounces went off on small pensions, he having made the tenement in Cursitor-street too warm to contain them; and in short, comported and demeaned himself in every respect like an unmitigated old Saracen, as he was. (...); (...)John Dounce, having lost his old friends, alienated his relations, and rendered himself ridiculous to everybody, made offers successively to a schoolmistress, a landlady, a feminine tobacconist, and a housekeeper; and, being directly rejected by each and every of them, was accepted by his cook, with whom he now lives, a henpecked husband, a melancholy monument of antiquated misery, and a living warning to all uxorious old boys.

${ }^{16}$ Do original: "There were Mr. Harris, the law-stationer, and Mr. Jennings, the robe-maker (two jolly young fellows like himself), and Jones, the barrister's clerk—rum fellow that Jones—capital company — full of anecdote!'

${ }^{17}$ Do original: "(...) a young lady of about five-and-twenty, all in blue, and all alone-splendid creature, charming face and lovely figure!; (...). If the young lady had appeared beautiful by night, she was perfectly irresistible by day". 


\section{Revista do SELL}

v. 5 , no. 2

ISSN: $1983-3873$

A supramencionada jovem, tendo extraído lucro suficiente e proventos da ligação com John Dounce, não apenas recusou-se, em momentos de crise, a aceitá-lo para o melhor ou o pior, como declarou expressamente, usando suas próprias palavras, que "não o desposaria por preço algum". ${ }^{18}$

Portanto, o retrato humorístico das personagens em "O malfadado caso do Sr. John Dounce", assim como em "As quatro irmãs" é feito através de recursos discursivos como os adjetivos, aspas e os diálogos inseridos pelo narrador, os quais não deixam de inferir a crítica social, aspectos históricos e culturais.

\section{Considerações finais}

A análise de "As quatro irmãs" e "O malfadado caso do Sr. John Dounce", em Sketches by Boz, de Charles Dickens, é baseada em aspectos discursivos da linguagem aliados às questões culturais, históricas e sociais, resultando na construção de um texto com descrições detalhadas e humorísticas que formam cenários mentais do cotidiano de homens e mulheres na sociedade vitoriana. O tema presente nas duas crônicas contrasta a visão burguesa e decadente do homem e da mulher na sociedade, assim como os valores puritanos da sociedade vitoriana pregados, mas, não colocados em prática.

As crônicas são textos narrativos marcados pelo humor, pois percebe-se o uso de recursos discursivos como os adjetivos, aspas e os diálogos, principalmente na descrição das personagens, com o objetivo de formar uma imagem caricata do homem e da mulher burguesa. Enquanto textos híbridos, as crônicas apresentam estruturas textuais do romance, como tempo, espaço, enredo com introdução, desenvolvimento e clímax, porém, em menor extensão. A crônica "O malfadado caso do Sr. John Dounce" apresenta no desfecho uma moral para a história como em fábulas ou contos de fadas. E, por fim, os vários diálogos com descrições detalhadas formam cenários mentais, como no texto teatral; e os relatos feitos pelo narrador parecem notícias, devido a linguagem objetiva como a do texto jornalístico.

\footnotetext{
18 Tradução do original: “. The last-mentioned young lady, having derived sufficient profit and emolument from John Dounce's attachment, not only refused, when matters came to a crisis, to take him for better for worse, but expressly declared, to use her own forcible words, that she 'wouldn't have him at no price".
} 


\section{Revista do SELL}

v. 5 , no. 2

ISSN: $1983-3873$

\section{Referências}

ARNT, Héris. Jornalismo e ficção: as narrativas do cotidiano. Rio de Janeiro, 2004. In Contemporânea, $\mathrm{n}$ 3, 2004-2. Disponível em: http://www.contemporanea.uerj.br/ pdf/ed_03/contemporanea_n03_05_arnt.pdf. Acesso em: 04/02/14.

BERGSON, Henri. O riso. Traduçao de Nathanael C. Caixeiro. 1983.

CANDIDO, Antonio. A vida ao rés-do-chão. In: A crônica. 0 gênero, sua fixação e suas transformações no Brasil. Campinas; Rio de Janeiro: Ed. da Unicamp; Fundação Casa de Rui Barbosa, 1992, p. 13-22.

COCKSHUT, A. O. J. The imagination of Charles Dickens. New York: Routledge, 2009, vol. 3

Dicionário da Mitologia Grega e Romana. Pierre Grimal, 5a edição, Editora BertrandBrasil, 2005.

DICKENS, Charles. Retratos Iondrinos. Tradução de Marcello Rollemberg. Rio de Janeiro: Record, 2003.

DICKENS, Charles. Sketches by boz. Pensylvania: The Pensylvania State University. 2000

DICKENS, Charles. Sketches by Boz: illustration of every-day life and every-day people. Lea \& BLanchard, 1839.

EAGLETON, Terry. Teoria da literatura: uma introdução. Martins Fontes, 2003.

GANCHO, C. V. Como analisar narrativas. Editora Ática, 2004. Disponível em:http://fortium.edu.br/blog/fabricio_martins/files/2012/02/ComoAnalisar

Narrativas_Gancho.pdf. Acesso em: 20/05/14.

GISSING, George. Charles Dickens: A critical study. Stroud: The History Press, 2012.

HUNTER, Adrian. The Cambridge introduction to the short story in English. Cambridge University Press, 2007.

JORDAN, J. O. Ed. The Cambridge companion to Charles Dickens. New York:

Cambridge University Press, 2001. Disponível em:

http://books.google.com.br/books?hl=ptB

$R \& \mid r=\& i d=w P e 7 u C b G v P U C \& o i=f n d \& p g=P R 9 \& d q=$ charles + dickens + biography \&ots $=$ ztdhMQXnD9\&sig=KMLUdlhYOVenr5rw32zKRCsP3U\#v=onepage\& $q=$ charles\%20dic kens\%20biography\&f=false. Acesso em: 20/05/14.

KAPLAN, Fred. Dickens: A Biography. New York: Open road integrated media, 2013. 


\section{Revista do SELL}

v. 5 , no. 2

ISSN: $1983-3873$

MOUTA, Margarida Amélia de Sá Vieira. Linguagem, transgressão e disfuncionalidade: uma abordagem enunciativo-pragmática do humor na comunicação verbal. (1996). Disponível em: http://repositorioaberto.up.pt/bitstream/10216/18105/2/FLM08201P00007

9331.pdf. Acesso em: 20/05/14.

ROLLEMBERG, Marcello. Um caso de jornalismo fantástico. In. DICKENS, Charles. Retratos Londrinos. Tradução de Marcello Rollemberg. Rio de Janeiro: Record, 2003.

ROLLEMBERG, Marcello. Algumas considerações sobre a Organização e a Tradução. In. DICKENS, Charles. Retratos Londrinos. Tradução de Marcello Rollemberg. Rio de Janeiro: Record, 2003.

SÁ, Jorge. A crônica. São Paulo: Ed. Ática, 2005.

SHNEIDER, C.I. Crônica jornalística um espelho para a história do cotidiano. In Revista Advérbio \# $05 . \quad$ São Paulo. 2011. Disponível em: http://www.fag.edu.br/adverbio/v5/artigos/cronica_jornalistica.pdf. Acesso em: 13/02/13.

SLATER, Michael. Dickens and women. London: Standford University Press, 1983.Disponível em: http:

//books.google.com.br/books?hl=ptBR\&lr=\&id=GyuH6eZZaQC\&oi=fnd\&pg=PR6\&dq=dicke ns+and+womem\&ots=xLzL2hcQNJ\&sig=EY8ZS6a2dUEIEbMbcDhIBP_ZGXM\#v=onepag e\&q=dickens\%20and\%20womem\&f=false. Acesso em: 20/05/14.

The Oxford Dictionaries. Disponível em: http://www.oxforddictionaries.com/definition/ english/time-and-tide-wait-for-no-man. Acesso em: 20/05/14.

The Phrase Finder. Disponível em: http://www.phrases.org.uk/meanings/384000.html. Acesso em: 20/05/14. 